\title{
Electrical properties of aggregated detonation nanodiamonds
}

Cite as: Appl. Phys. Lett. 93, 132115 (2008); https://doi.org/10.1063/1.2996026

Submitted: 08 September 2008 . Accepted: 15 September 2008 . Published Online: 03 October 2008

Mose Bevilacqua, Sameer Patel, Aysha Chaudhary, Haitao Ye, and Richard B. Jackman

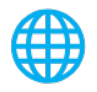

\section{ARTICLES YOU MAY BE INTERESTED IN}

\section{Electrical properties of monodispersed detonation nanodiamonds}

Applied Physics Letters 96, 242903 (2010); https://doi.org/10.1063/1.3446966

Nanocrystalline diamond as an electronic material: An impedance spectroscopic and Hall effect measurement study

Journal of Applied Physics 107, 033716 (2010); https://doi.org/10.1063/1.3291118

Electrical conductivity of thermally hydrogenated nanodiamond powders

Journal of Applied Physics 113, 214307 (2013); https://doi.org/10.1063/1.4809549

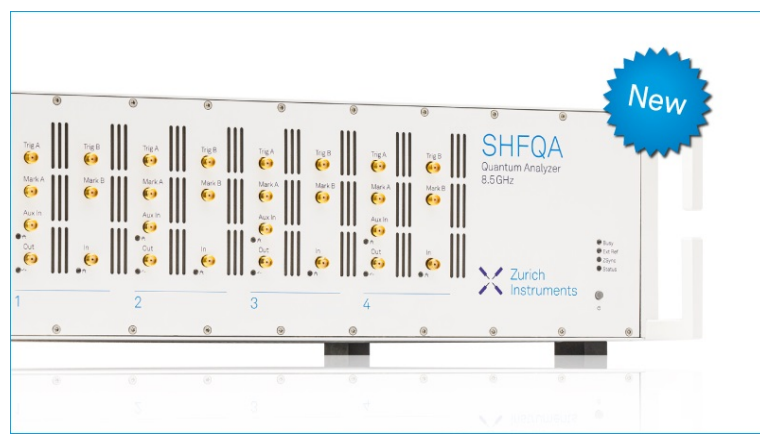

\section{Your Qubits. Measured.}

Meet the next generation of quantum analyzers

- Readout for up to 64 qubits

- Operation at up to $8.5 \mathrm{GHz}$,

- Signal optimization with minimal latency

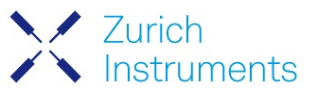




\title{
Electrical properties of aggregated detonation nanodiamonds
}

\author{
Mose Bevilacqua, Sameer Patel, Aysha Chaudhary, Haitao Ye, and Richard B. Jackman ${ }^{\text {a) }}$ \\ London Centre for Nanotechnology, University College London, 17-19 Gordon Street, London WC1H \\ $O A H$, United Kingdom
}

(Received 8 September 2008; accepted 15 September 2008; published online 3 October 2008)

\begin{abstract}
Nanometer-scale diamonds formed using a detonation process are an interesting class of diamond materials. Commercially supplied material is highly aggregated with $\sim 5 \mathrm{~nm}$ diamond crystals forming particles with micron sizes. Previous models have suggested that nondiamond carbon is incorporated between the crystals, which would reduce the electrical and chemical usefulness of this form of diamond. However, using impedance spectroscopy we have shown that at temperatures below $350{ }^{\circ} \mathrm{C}$ the form of detonation nanodiamond being studied is a near to ideal dielectric, implying a full $s p^{3}$ form. At temperatures above this the surfaces of the diamond crystals may support some nondiamond carbon. (C) 2008 American Institute of Physics.
\end{abstract}

[DOI: $10.1063 / 1.2996026$ ]

There is considerable interest in the use of nanometerscale structured diamond for a wide range of applications. ${ }^{1}$ In terms of diamond powder, the most abundant material comprises $\sim 5 \mathrm{~nm}$ crystals of cubic diamond particles formed by detonating an oxygen-deficient trinitrotoluene (TNT)/ hexogen composition in inert media. ${ }^{2}$ This material is often referred to as "detonation nanodiamond (DND)." Little is known about the electrical properties of DND. This is in part due to the aggregated form of most DND powders, which may also be highly contaminated. ${ }^{3}$ In a study by Hamilton et $a l .{ }^{4}$ a model whereby "core" diamond crystals, created when unburnt carbon experiences the shock wave following detonation, are then surrounded by an aggregate of "sootlike" material after the shock wave passes was proposed. The tenacious nature of the aggregates, such as their resistance to acids, was explained on the basis of a diffusion-limited reaction, with little oxidation occurring between the diamond grains. Pershin et al. ${ }^{5}$ used x-ray absorption and emission studies to determine that aggregated (acid treated) DND comprises around $21 \% s p^{2}$ carbon material. However, Kuznetsov et al. ${ }^{6}$ investigated the electrical resistivity of DNDs using the four-point probe method; in their case the material was highly resistive unless it was heated above $1100 \mathrm{~K}$, at which point the resistivity dropped due to the formation of graphitic phases. In this case the authors considered that their acid treatment of the DND had removed all graphitic phases. It is clear that a better insight into the electrical properties of DNDs is required; in this letter we begin this process by using impedance spectroscopy (IS) to investigate electrical conduction paths within aggregated DND powders.

IS has been previously deployed to study the properties of single crystal and polycrystalline diamond films to some effect. $^{7-10}$ In essence, the technique involves the measurement of the real and imaginary components of the films impedance as a function of both frequency and temperature. The impedance as a complex number can be defined as

$$
Z(\omega)=\operatorname{Re}(Z)+j \operatorname{Im}(Z),
$$

where the real part refers to resistive contributions and the imaginary part refers to the capacitative. Hence any contri-

\footnotetext{
${ }^{\text {a) }}$ Author to whom correspondence should be addressed. Electronic mail: r.jackman@ucl.ac.uk.
}

butions to the over all impedance measured that have strongly differing $R C$ components can be identified. In a typical IS analysis, the impedance is measured as a function of frequency, and the real component plotted against the imaginary component as the frequency is changed. These so-called Cole-Cole plots may then reveal differing semicircular responses for each $R C$ component of the film.

DND powder (SuperSyndia SSX 0-3.5) was investigated in the "as-received" condition. Scanning electron microscopy images of a typical particle are shown in Fig. 1. In Fig. 1(a) a typical aggregated "grain" can be seen to have an over all dimension of the order of $3 \mu \mathrm{m}$, while in Fig. 1(b) it is just possible to discern extremely small nanometer-scale crystals aggregated to grains of 30-100 nm sizes which in turn make up the $3 \mu \mathrm{m}$ particle. It was impractical to carry out IS on a single particle, hence a multiplicity of grains was placed be-

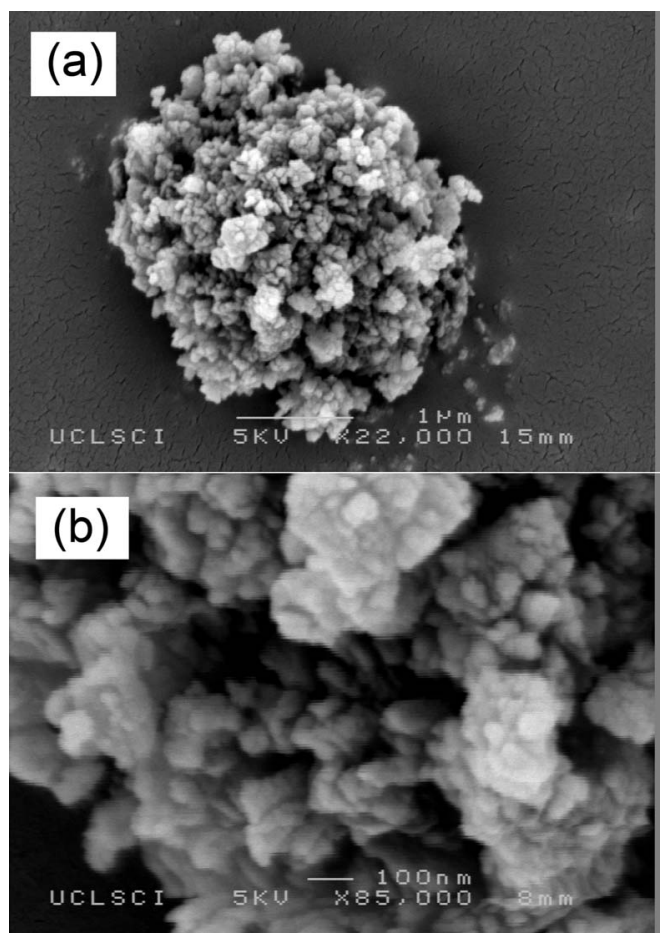

FIG. 1. Scanning electron microscope pictures of the DND used revealing (a) typical grain size and (b) the densely agglomerated nature of the DND crystals. 
(a)

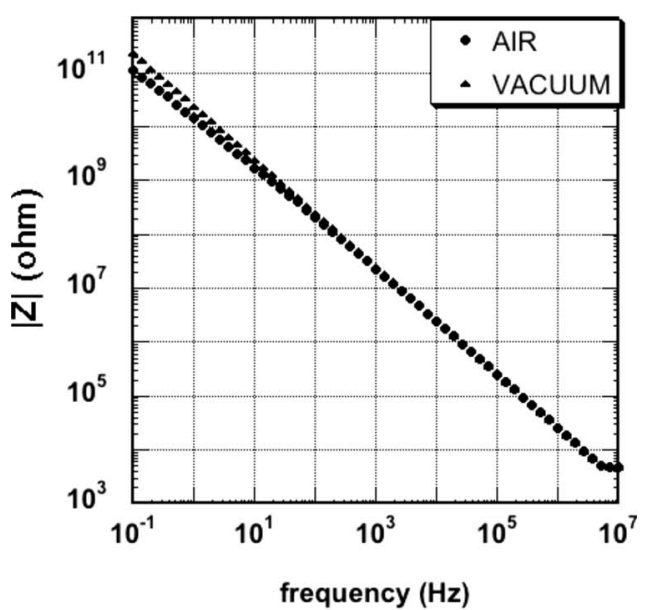

(b)

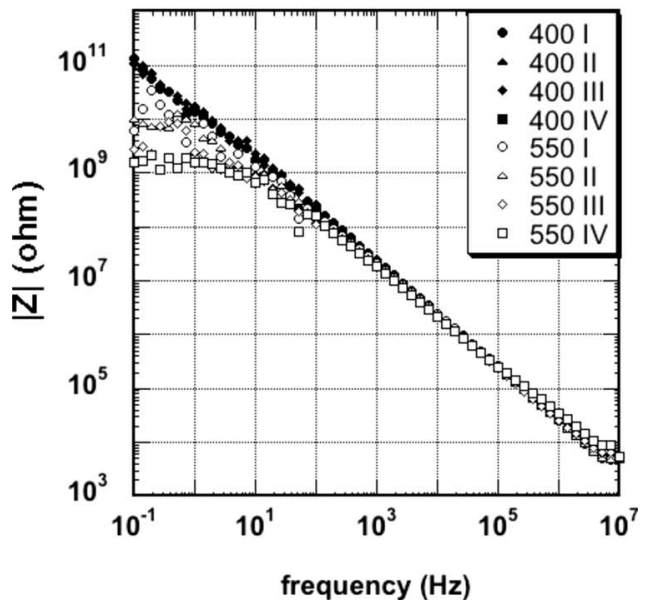

FIG. 2. Real impedance plotted against measurement frequency for (a) DND powder measured in air and vacuum at room temperature and (b) DND powder measured at 400 and $550{ }^{\circ} \mathrm{C}$ in air.

tween two tantalum disks. IS was performed over the frequency range $0.1 \mathrm{~Hz}-10 \mathrm{MHz}$ (Solartron 1260 impedance system with Solartron 1296 dielectric interface). All experiments were carried out inside a stainless steel vacuum chamber (base pressure $\sim 10^{-3}$ mbar), which allowed both electrical screening and control of the ambient gas.

IS experiments were carried out both in vасиo and in air. Figure 2(a) shows the real impedance plotted against the measurement frequency at room temperature in both cases; it can be seen that the DND material has a very high low frequency resistance and that the ac resistance remains high beyond a measurement frequency of $1 \mathrm{MHz}$. The low frequency resistance can be seen to be a factor of 2 lower in the case of the air measurement compared to vacuum, but this difference is lost once the measurement frequency exceeds $100 \mathrm{~Hz}$. Figure 2(b) shows similar data, recorded in air, but at temperatures of 400 and $550{ }^{\circ} \mathrm{C}$. In each case the measurement was performed several times. Interestingly, the measurements at $400{ }^{\circ} \mathrm{C}$ are both stable when repeated and almost identical to those recorded at room temperature. However, at $550{ }^{\circ} \mathrm{C}$ the curves can be seen to decrease in resistivity with increasing measurement cycle, with the low frequency resistance falling by almost two orders of magnitude. (a)

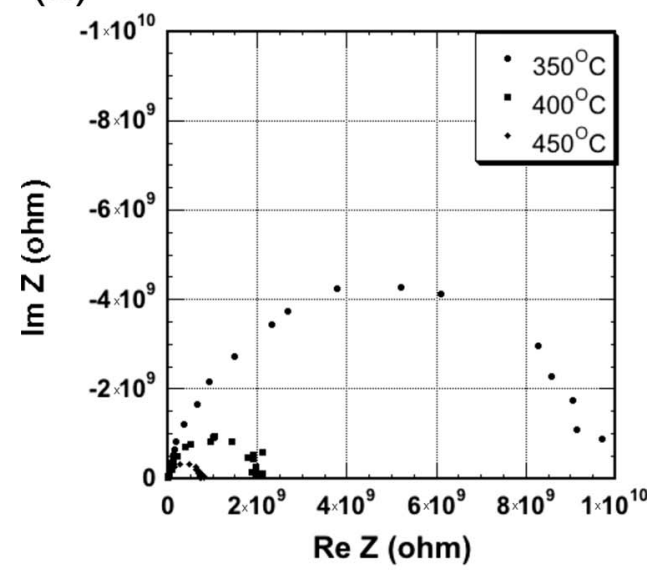

(b)

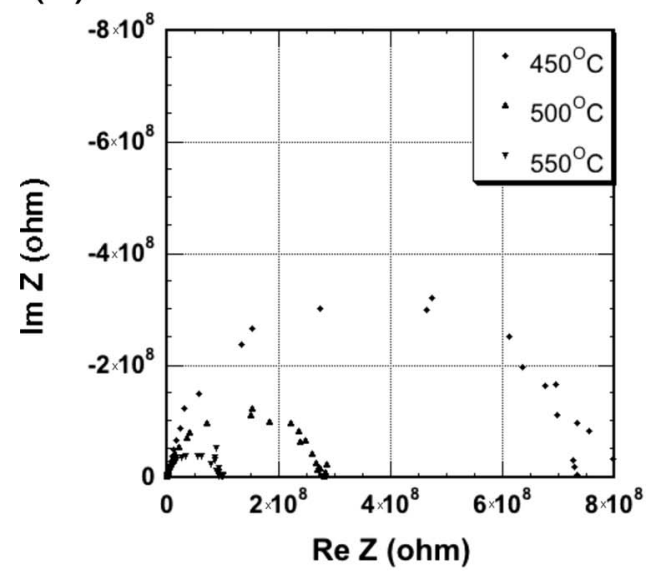

(c)

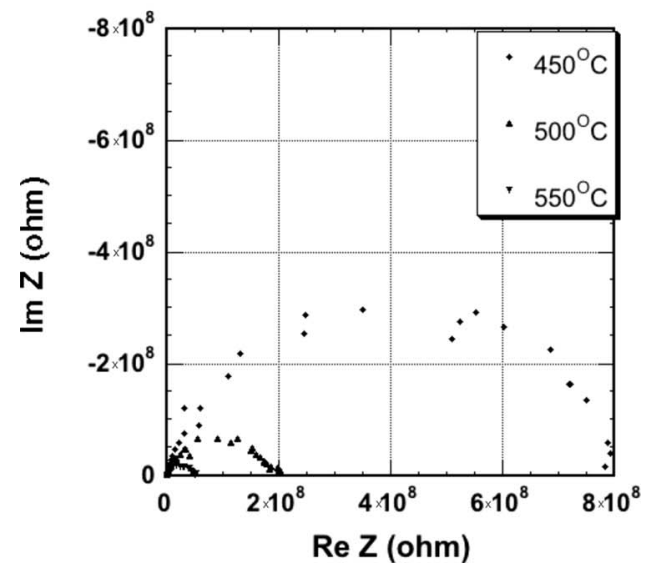

FIG. 3. Cole-Cole plots for DND powders measured in air at (a) $350-450{ }^{\circ} \mathrm{C}$, (b) $450-550{ }^{\circ} \mathrm{C}$, and (c) $450-550{ }^{\circ} \mathrm{C}$ after several measurement cycles.

Electrical conduction through the films could only be measured at temperatures of $350^{\circ} \mathrm{C}$ and above Figure 3(a) shows Cole-Cole plots, measured in air, recorded at 350, 400 , and $450{ }^{\circ} \mathrm{C}$. Single semicircular responses can be seen which decrease in size with increasing temperature. Similar data are shown in Fig. 3(b) for measurements at $450-550{ }^{\circ} \mathrm{C}$, where the same trend can be seen. Figure 3(c) shows data recorded at $450-550{ }^{\circ} \mathrm{C}$ after a total of four measurement cycles. The trend with temperature remains the same, but the over all magnitude of the semicircular response can be seen to have decreased since the first measurements were performed at these temperatures. 
Extrapolation of the line displayed in Fig. 2(a) to zero frequency enables the dc resistivity of the film to be determined, revealing a value greater than $10^{13} \Omega /$ sq. This value is typical for the highest quality polycrystalline chemical vapor deposition (CVD) material ${ }^{11}$ and remarkably close to values obtained for single crystal diamond. This is an excellent result given that this is nanostructured detonation powder, which has often been considered to comprise a composite of $s p^{3}, s p^{2}$, and impurity species. ${ }^{2-4}$ An important characteristic of an insulating film is the dielectric loss tangent $(\tan \delta)$, determined as a function of ac frequency. $\tan \delta$ is the imaginary part of the complex dielectric constant as a ratio with its real component. For the data shown in Fig. 2(a), $\tan \delta$ is around 0.3 at $0.1 \mathrm{~Hz}$, falling to 0.02 at $1 \mathrm{MHz}$ for the air measurements, and 0.04 falling to less than 0.01 for the vacuum measurements. It should be remembered that the function $\tan \delta$ is a measure of the ratio of the power dissipated in the dielectric to the power stored, implying low numbers are desirable. Lu et al. ${ }^{12}$ investigated the dielectric properties of very large grain thick freestanding diamond films $(0.3-1.5 \mathrm{~mm})$. Over the frequency range we have investigated here they observed an increasing value of $\tan \delta$ from 0.05 to 0.085 , while in our case the trend in the data is the opposite. The decreasing trend is a desirable feature since it shows the dielectric loss is decreasing with increasing frequency. In another report on the use of commercially available thick CVD polycrystalline diamond films, Ibarra et al. ${ }^{13}$ measured a dielectric loss tangent of around 0.01 falling to around 0.001 at $10 \mathrm{MHz}$. In this case the trend is similar to that we observe here, decreasing with increasing frequency, and with similar values, at least for the vacuum measurements performed. The DND samples can be considered as a three-dimensional network of the nanodiamond particles. They are not continuous films, rather they contain many interfaces formed by the surface of the nanodiamond particles and voids where the irregular particles are not perfectly packed. Due to the large specific surface area of the nanodiamond particles, the interfaces should play an important role on the electronic properties of the material. It is thus surprising that the dielectric properties are similar to single crystal diamond, indicating that this particular DND powder is principally an $s p^{3}$ material, even at the boundaries between the agglomerated nanocrystals. The fact that little change is evident in the data recorded at $400{ }^{\circ} \mathrm{C}$ [Fig. 2(b)] indicates good stability of this dielectric material to this temperature. This is not so at $550{ }^{\circ} \mathrm{C}$ [Fig. 2(b)] showing that changes to the film are now occurring, as the reduction in impedance values (and an increase in the value of $\tan \delta$ ) is not reversible. The most obvious explanation would be the onset of $s p^{2}$ formation in the DND powder at this temperature; this is discussed further below.

The Cole-Cole plots in Fig. 3 indicate that electrical conduction through the films can be detected at temperatures greater than $350{ }^{\circ} \mathrm{C}$. The reduction in the magnitude of the semicircular response with increasing temperature indicates that the powder sample becomes more conductive as the temperature increases, which is expected behavior. The fact that only a single semicircular response is seen is interesting. In previous studies of diamond using IS, more than one semicircular response has often been observed, ${ }^{7-10}$ indicating more than one conduction path. In the case of polycrystalline and nanocrystalline diamond films, this observation has been attributed to conduction through both the grains and grain boundaries. The fact that only one semicircle is seen here indicates that a single conduction path exists. Mathematical fitting to the semicircles can lead to the values of $R$ and $C$ associated with it to be determined. For the data contained in Fig. 3 for $350{ }^{\circ} \mathrm{C}$ the capacitance values all lie in the picofarad range. It has been previously shown that grain interior conduction displays capacitance values of this order, where as grain-boundary conduction more often displays nanofarad values. ${ }^{14}$ Hence, it is possible to suggest that the surfaces and interfaces between the nanometer-scale diamond crystals within the agglomerated particles are not supporting a second form of electrical conduction when compared to that derived from the crystal interiors at this temperature. However, for the semicircles measured at $550{ }^{\circ} \mathrm{C}$ after a number of measurement cycles display capacitance values in the $1-10 \mathrm{nF}$ range, indicative of grain-boundary type conduction; it can be suggested that the nanometer-scale crystals that are agglomerated to form the $\mu \mathrm{m}$ size particles, are not stable in the $s p^{3}$ form as they are heated to $550{ }^{\circ} \mathrm{C}$, and that some degree of $s p^{2}$ formation, presumably at the boundaries between the agglomerated crystals, is now occurring.

The form of DND studied here has been found to be highly resistive, and capable of performing as a near to ideal dielectric at temperatures below $350{ }^{\circ} \mathrm{C}$. This is contrary to some previous observations and challenges the idea that the nanometer-sized detonation-formed diamond crystals agglomerate together via a network of non-s $p^{3}$ carbon that is impervious to annealing and/or acid treatments. Indeed, the measurements performed here suggest that only one form of electrical conduction occurs within these materials, which is grain-interior-like at temperatures below $350{ }^{\circ} \mathrm{C}$, but may be due to surface/interface conduction at higher temperatures. This implies that these diamond powders may be suitable for several applications where chemically functionalizing nanometer-scale $s p^{3}$ material is desirable, and for those requiring a dense dielectric powder material under either dc or high frequency conditions.

${ }^{1}$ Synthesis, Properties and Applications of Ultrananocrystalline Diamond, Nato Advanced Studies Institute, Science Series, edited by D. M. Gruen, O. A. Shenderova, and A. Y. Vul (Spinger, Netherlands, 2005), Vol. 192.

${ }^{2}$ O. A. Shenderova, V. V. Zhirnov, and D. W. Brenner, Crit. Rev. Solid State Mater. Sci. 27, 227 (2002).

${ }^{3}$ A. Krüger, F. Kataoka, M. Ozawa, T. Fujino, Y. Suzuki, A. E. Aleksenskii, A. Ya. Vul', and E. Ōsawa, Carbon 43, 1722 (2005).

${ }^{4}$ T. Hamilton, E. Z. Kurmaev, S. N. Shamin, P. Y. Detkov, S. I. Chukhaeva, and A. Moewes, Diamond Relat. Mater. 16, 350 (2007).

${ }^{5}$ S. V. Pershin, E. A. Petrov, and D. I. Tsaplin, Combust., Explos. Shock Waves 30, 235 (1994).

${ }^{6}$ V. L. Kuznetsov, Yu. V. Butenko, A. L. Chuvilin, A. I. Romanenko, and A. V. Okotrub, Chem. Phys. Lett. 336, 397 (2001).

${ }^{7}$ H. Ye, O. A. Williams, R. B. Jackman, R. Rudkin, and A. Atkinson, Phys. Status Solidi A 193, 462 (2002).

${ }^{8}$ H. T. Ye, R. B. Jackman, and P. Hing, J. Appl. Phys. 94, 7878 (2003).

${ }^{9}$ H. T. Ye, O. Gaudin, R. B. Jackman, P. Muret, and E. Gheeraert, Phys. Status Solidi A 199, 92 (2003).

${ }^{10}$ S. Curat, H. Ye, O. Gaudin, R. B. Jackman, and S. Koizumi, J. Appl. Phys. 98, 073701 (2005).

${ }^{11}$ A. Huanosta and A. R. West, J. Appl. Phys. 61, 5386 (1987).

${ }^{12}$ F. X. Lu, H. D. Zhang, Y. M. Tong, J. X. Yang, C. M. Li, G. C. Chen, and W. Z. Tang, Diamond Relat. Mater. 13, 1714 (2004).

${ }^{13}$ A. Ibarra, M. Gonzalez, R. Vila, and J. Molla, Diamond Relat. Mater. 6, 856 (1997).

${ }^{14}$ L. L. Hench and J. K. West, Principles of Electronic Ceramics (Wiley, New York, 1989), Chap. 5 